\title{
O TRABALHO EM CARNE VIVA. OBSERVAÇÃO PARTICIPANTE DO TRABALHO OPERÁRIO
}

Bruno Monteiro

\section{Introdução}

Este texto procura restituir a importância da carnalidade como instância crucial da experiência social do trabalho operário. Em vez de transigir com concepções tecnicizadas do trabalho, esta pesquisa etnográfica visa estudar os processos de incorporação que acompanham a presença prolongada dos operários na fábrica. De maneira a submeter o universo das expressões somáticas do operariado a uma pesquisa etnográfica sistemática e controlada, o investigador usou o seu próprio corpo como mecanismo de objectivação sociológica. Expondo-se a um contacto proximal e reiterado com as vicissitudes do trabalho fabril, o investigador procurou captar as competências incorporadas que são impostas e solicitadas pela experiência quotidiana da fábrica, as categorias de percepção que são aplicadas pelos trabalhadores e as circunstâncias materiais e sociais que suportam a espessa sociabilidade operária.

Desta maneira, o investigador recorreu à observação participante para registar as vicissitudes pelas quais passa a relação de pertença mútua entre trabalhadores e contexto de trabalho, a nuvem de pequenas palavras e movimentos que preenchem as interacções mais triviais da fábrica, ou as práticas inconscientes e silenciosas que acompanham a execução das actividades laborais. Por acréscimo, ao interrogar os contrastes que surgiam entre as suas acções e reacções e, por outro lado, as sensações e as expressões viscerais dos operários, houve oportunidade para o investigador monitorizar em tempo real, a partir do seu próprio corpo, a progressiva inculcação, a condensação e a actualização dos esquemas de acção e pensamento que caracterizam os trabalhadores. Pela explicitação sociológica de tais contrastes, o investigador pôde objectivar os trajectos de incorporação particulares que caracterizam ele próprio e os operários, relevando e circunscrevendo, com isso, as variações sociais que pesam sobre a carnalidade, tantas vezes vista como uma constante "biológica" ou "natural". 
Tornando o seu corpo plataforma de interrogação, o investigador pôde, portanto, conhecer a lógica da economia corporal da fábrica. Os eixos de estruturação da vida fabril estão organizados em torno do corpo operário, que constitui o ponto de incidências dos mecanismos de regulação produtiva e, simultaneamente, o reservatório para as vantagens económicas e simbólicas que os operários procuram com o trabalho fabril. Nestas circunstâncias, em pleno processo de trabalho, a regularização e a exploração dos corpos operários pelas tecnologias patronais ou, pelo contrário, a conservação da sua integridade e expressividade pelos próprios trabalhadores tornam o corpo uma parada de luta no contexto da fábrica. No entanto, esta pesquisa não implica pensar unicamente o plano interaccional do trabalho. A proposta de Michael Burawoy para a observação participante sugere, precisamente, que “a observação participante pode examinar o macromundo através do modo como este último molda e, por sua vez, é moldado e condicionado pelo micromundo, o mundo quotidiano da interacção face a face" (Burawoy 1991:6).

Deste modo, torna-se possível relacionar a instilação das regularidades temporais e comportamentais que ocorre no interior da fábrica, o regime de valor económico e simbólico que acompanha o trabalho operário, ou o apuramento dos limiares sensoriais e emocionais dos trabalhadores com as trajectórias biográficas que caracterizam, singular e colectivamente, o operariado da comunidade sob pesquisa, por um lado, e com o estatuto particular que o corpo operário tem em regime de produção capitalista, por outro lado. Numa comunidade industrial como Rebordosa, onde se situa a empresa sob observação, prevalecem indicadores que testemunham a existência de reduzidos patamares de escolaridade, o que se translada num acesso precoce e subalterno ao mercado de trabalho, e a significativa concentração de postos de trabalho num sector de actividade específico, a indústria do mobiliário, que necessariamente actua como ponto de fixação para as pretensões profissionais dos seus habitantes, embora esteja marcada por baixos salários e pela forte "crise" económica que recentemente percorre a região do Vale do Sousa (vd. Queirós \& Pinto 2010). ${ }^{1}$

\section{Pensar as diferenças entre corpos: observação participante e reflexividade sociológica}

Para compreender integralmente a tessitura da experiência social do operariado é necessário admitir a relevância da carnalidade para as suas maneiras de ser, estar e ver específicas (vd. Charlesworth 2000). A condição operária é corporalmente vivida, tendo no corpo dos operários um índice 
que exprime e um factor que recria o seu universo material e simbólico. A presente investigação procurou, de fato, recuperar sociologicamente essa economia corporal do trabalho operário que tende a permanecer em estado implícito e inconsciente, inclusive para os seus portadores, embora esteja constantemente activa pela aquisição, a actualização e a transmissão das práticas laborais e pela constituição de traços relevantes da cultura somática do operariado local. Em virtude da opção tomada, esta pesquisa vai, assim, impedir que se menospreze a componente visceral da experiência operária, tentando, ao invés, proporcionar uma via suplementar para a compreensão da "lógica da arte" (Lopes 1976:98).

Nesta pesquisa, a "realidade das condições de trabalho" e as suas "representações espontâneas", para retomar os termos de José Sérgio Leite Lopes (1976:140), serão pensadas a partir da relevância do corpo operário para o trabalho fabril, o que implicou imbricar as minuciosas exposições sobre a actividade e a sensibilidade dos operários em pleno trabalho com as narrações dos operários sobre os eventos laborais. Não se pretende reivindicar uma autoridade insuperável para a observação participante, tão somente salientar as suas virtualidades para trazer um registo sobre as circunstâncias vividas e imediatas que acompanham o trabalho. Assim, esta opção de investigação pode ser usada para suplementar outro tipo de pesquisas, proporcionando o acesso a vertentes da realidade fabril, como a experiência visceral do trabalho ou os instantes vividos do evento laboral, que são, por vezes, menosprezados ou omitidos pela investigação sociológica.

Neste caso em particular, o corpo do investigador vai ser usado ao mesmo tempo como "instrumento de investigação" e como "vector de conhecimento" para captar a carnalidade da existência operária (Wacquant 2002:11). De maneira a concretizar esta sociologia carnal foi realizado um trabalho de observação participante numa fábrica de mobiliário - a empresa $\mathrm{K}$ - o que significou para o investigador trabalhar, ao longo de 14 semanas, como manobrador de máquinas e como auxiliar de produção (vulgo, "moço"). A empresa K dedica-se ao fabrico de mobiliário, reunindo as sucessivas fases do seu processo de produção: criação mecanizada de componentes pelos "maquinistas"; montagem semiartesanal por marceneiros; acabamento e envernizamento; por fim, expedição para os revendedores, que comercializam os móveis para o público.

A empresa tinha 35 trabalhadores, estava relativamente bem equipada em termos tecnológicos, e tinha uma gerência profissional e não exclusivamente familiar - características relativamente raras no âmbito local. ${ }^{2}$ Para o acesso a esta empresa, foram utilizados os contactos pessoais, inicialmente criados em sede da escola preparatória e dos espaços de sociabilidade juve- 
nil frequentados em comum, que o investigador mantinha com um operário então empregado pela empresa; por via de um tal interlocutor, foi possível conseguir a necessária permissão patronal para começar a trabalhar. Em face dos outros trabalhadores, o investigador assumiu, à partida, a sua missão sobre o terreno, tanto mais que era evidente pelos seus sinais mais ostensivos, como o corpo ou a linguagem, que ele não tinha um contacto prévio com o ofício em causa. À medida que o tempo passava, verificou-se uma progressiva inscrição do investigador nas teias de urgências e compromissos que cruzavam a empresa: as tarefas que ele realizava eram necessárias e prementes para outros trabalhadores, o convívio com os colegas multiplicava as trocas sociabilitárias, a prorrogação da sua presença diante das máquinas tornou-a habitual. Esta submissão em comum aos acontecimentos da vida fabril terminou por encastrar a figura do investigador na paisagem fabril. $\mathrm{Na}$ verdade, porém, os seus colegas nunca se mostraram especialmente curiosos sobre a natureza da pesquisa, que permaneceu para eles sempre como um mero "trabalho para a escola".

O investigador regressaria mais tarde, em 2008, para viver mais 16 semanas na comunidade em que se situa a empresa, requisito indispensável para ele poder participar dos lugares de sociabilidade do operariado local, tais como cafés, ginásios, centros de emprego, centros de saúde, ou clubes de futebol, que se interligam e que envolvem o contexto de trabalho fabril em sentido estrito, a fábrica. Neste texto, porém, será sobre a pesquisa etnográfica realizada sobre o chão da fábrica que se constituirá o ponto de inflexão principal.

Esta prolongada implantação sobre o terreno permitiu um enraizamento nas redes de interconhecimento local que facilitaram a marcação e a realização de entrevistas. Durante a sua permanência ali, o investigador teve ocasião de aplicar 35 entrevistas aprofundadas aos operários ou às suas famílias. Dado que se pretendia minorar a natureza impositiva que elas podem ter, privilegiou-se sempre a realização das entrevistas em locais considerados protegidos pelos próprios entrevistados, em especial a sua habitação; sempre que possível, as entrevistas prolongavam-se por mais do que uma sessão, o que permitia retomar para esclarecimentos a conversa iniciada previamente. Depois de transcritas, as entrevistas foram tratadas e analisadas por recurso a procedimentos sociolinguísticos que visam, em particular, investigar as implicações propriamente linguísticas que têm as propriedades sociais dos entrevistados (entre outras, o tom e a acentuação de certas palavras, o vocabulário, os raciocínios e as associações de motivos ou temas, ou os resmoneares e os interditos), razão pela qual se optou por usar excertos suficientemente extensos para expor as particularidades das enunciações dos entrevistados (Niethammer 2012:37-50). 
Neste sentido, visou-se não só compilar uma constelação de referências verbais sobre o modo de vida operário, mas também expor as modalidades de estilização discursiva (e as barreiras à sua articulação) que são relevantes para os operários, vendo, numas e noutras, vertentes de uma maneira integrada de discernir e apreciar o mundo social (vd. Baxandall 1988). Por outras palavras, em vez de isolar e escrutinar apenas as unidades de informação tidas por relevantes para a transmissão de conhecimento, procurou-se, por acréscimo, patentear os hábitos de pragmática discursiva, os procedimentos de interpretação intelectual e as tácticas para lidar e investir com sentido o mundo social, todas elas vertentes verbais e emocionais que são solidárias do lugar social particular ocupado pelos operários em causa (Watts 2003:250-263).

Para investigar sociologicamente os processos de incorporação das competências laborais que são características de um operariado territorialmente situado, os seus quadros de interacção habitual foram usados como postos de observação etnográfica. Permanecer longamente sobre os locais, habitando-os, vai fixar variedades de percepção e os limiares de sensibilidade, pautar o reportório emocional e intelectivo, e modular as poses e as posturas dos seus ocupantes habituais (Charlesworth 2000:64-65). Esta opção permite ao investigador "organizar a sua experiência das outras culturas ao incorporá-las de determinadas maneiras" e conduz, por seu lado, a pensar o contexto sob investigação como "o conjunto de referências gerado pela interacção entre os sentidos" (Howes 1990a:62).

O trabalho etnográfico, conduzido directamente sobre os locais de reprodução da existência quotidiana de uma comunidade industrial do Noroeste português, em particular a fábrica, permitiu registar em tempo real as circunstâncias da instilação e da concretização das práticas operárias. Vendo em estado vivo os padrões de sentimento, os modos de atenção e os regimes de valorização ética que caracterizam este operariado, torna-se possível pensar sobre vertentes tácitas e silenciosas da existência operária, tantas vezes omitidas ou reprimidas nas pesquisas que apenas privilegiam os signos ou os textos (Csordas 1990).

Esta submissão teoricamente controlada do corpo e da situação social do investigador aos condicionamentos que pesam sobre um conjunto de indivíduos social e espacialmente contextualizados visa permitir o acesso imediato às reacções mais subtis e espontâneas a uma situação social particular. Nos termos de Erving Goffman, a observação participante "sintoniza o teu corpo", e com o teu corpo "sintonizado" e com o direito ecológico de estar junto deles, estás em posição de registar as suas respostas gestuais, visuais, corporais ao que ocorre em redor deles e és suficientemente empático - 
porque tens vindo a sujeitar-te às mesmas tretas que eles - para sentir aquilo a que eles estão a reagir" (Goffman 1989:125-126). Por consequência, os registos etnográficos da paulatina sintonização do investigador com o mundo fabril, que podia ser avaliada por comparação com a consonância revelada pelos outros trabalhadores, mostram o sentido e as implicações do percurso modal de operário.

A natureza progressiva da sintonização do investigador com o universo material e simbólico da fábrica é que permite que a sua própria presença sobre o terreno possa ser pensada como um trajecto de conversão, cuja peculiaridade pode ser verificada pela constatação e a explicação dos contrastes em relação aos outros trabalhadores. "O que eu ouvia a princípio, antes de escutar verdadeiramente, era um caudal de comunicações estilhaçadas que não fazia muito sentido. [...] Mas à medida que comecei a prestar mais atenção, a familiarizar-me com a rede das comunicações, o incoerente tornou-se coerente, o absurdo ganhou sentido, o obscuro tornou-se claro e mesmo a estupidez se tornou divertida" (Roy 2006:165-166). Nestes termos, Donald Roy verifica precisamente a progressiva consonância dos seus comportamentos e pressentimentos em relação aos seus colegas, tal como ela ocorreu ao longo do tempo de permanência no local de trabalho que investigava.

Vimos já que submeter o envolvimento sensorial do investigador aos procedimentos de reflexividade permite superar a tradição de índole hermenêutica que tende a constituir e a interpretar a realidade social exclusivamente em termos de textualidade (Biernacki 1995:31-36). Nesta investigação, a presença do investigador será ela própria objectivada, usando-se este procedimento de autorreflexividade para tentar explicitar e controlar os possíveis enviesamentos que o investigador traz consigo, usualmente em estado inconsciente (e inconsciente porque incorporado). Em concomitância, este procedimento serviu para tentar captar em acto, a partir do registo das variações anotadas pelo investigador a respeito do seu próprio corpo, o progressivo movimento de incorporação das competências práticas do trabalho operário.

Por um lado, ao reconhecer que os contextos de pesquisa etnográfica, independentemente da sinceridade da proclamação de princípios éticos ("boas intenções", "emancipação"), são cruzados por relações sociais de observação que põem em interacção sujeitos que raramente estão em situações económica e culturalmente equivalentes, integramos uma vigilância epistemológica de si que preconiza e contempla o esclarecimento das condições sociais de observação (Bachelard 1960:120). Por outro lado, é possível registar a par e passo, em particular pela constatação dos contrastes em relação aos outros trabalhadores, a quem carecem razões válidas para explicitarem a sua habituação à fábrica, a formação de um corpo operário. 
Nas notas de campo que se seguem procuramos expor o trânsito paulatino do corpo do investigador no sentido de "ganhar corpo", isto é, o entumescimento do corpo do investigador com as capacidades ginásticas, sensoriais e cognitivas que permitem, a pouco e pouco, o reconhecimento pelo colectivo de trabalho dos sinais exteriores de habilidade e corpulência que sugerem a pertença nativa. Foram estes contrastes e a sua evolução ao longo do tempo que durou a pesquisa que permitiram tomar explicitamente consciência do processo de incorporação do corpo operário.

19 de Janeiro de 2007 - F. diz-me, às 12h20: "Vais ficar como um capado!" (Enquanto diz isto, eleva os ombros.) Refere-se obviamente à minha submissão às rotinas e à dureza do trabalho na orladora. "Já vês as veias [salientes] nos braços? Então, vais ver...".

14 de Março de 2007 - 12h30. Tiro a camisola para me limpar antes de sair para almoçar. F., que passa ao meu lado, comenta em voz alta: "Olha ele em t-shirt!", rindo-se e enchendo o peito enquanto o faz. U. olha para mim e, ao mesmo tempo que dá um salto para trás, como se tivesse ficado muito surpreendido, exclama: "Que cabedal!". Dirigindo-se a F., que se afastara entretanto, acrescenta: "Desde que veio para a fábrica já ganhou corpo, fez-se homem. Antes era a Maria..." [...] [Após o almoço. 15h30] "As mãos de estudante estão a ir para o tecto". Exibo-as de palmas voltadas para cima. "É bom sinal. É sinal que estás a ficar um homem". [...] [16h20] Queixo-me de dores nos dedos de uma mão. F. diz-me: "Agora aproveitas, puxas todos os dias. Assim, o teu corpo habitua-se e nem quer outra coisa".

3 de Abril de 2007 — Após o almoço, sentado no café. B., no café com Ricardo, diz: "Uma coisa tenho que admitir... A fábrica fez-lhe [a mim] ganhar corpo, até engrossou a barba. [...] Ricardo diz-lhe que para certificar-se da verdade dessa transformação tem "um critério que não falha". Agarra-me na mão e volta-a de palma para cima. "Andas a dar-lhe uma vida muita boa!", diz para B., no meio de risos, implicando uma suposta ausência de marcas na pele.

Desta maneira, em vez de tentar esquecer, menosprezar ou sublimar as variações existentes entre o corpo do investigador observador e os corpos dos operários observados (contrastes que variam, eles próprios, à medida que o investigador vê progredir as suas competências oficinais ao longo do tempo), tentamos introduzir a premência de uma explicitação e explicação do contraste entre os corpos, ou usos dos corpos, que os caracterizam e os singularizam. Este procedimento metodológico serve, como foi referido, 
para sinalizar e controlar as implicações que são introduzidas pela presença do investigador sobre o terreno e, por acréscimo, para explorar as incompreensões mútuas ou as clivagens verificadas entre os comportamentos do investigador e dos trabalhadores que se encontram em copresença. A comparação rigorosa e metódica da compostura, da habilidade, das aversões, dos apetites, e do menear dos operários, com a imperícia técnica, a perturbação emocional e a incapacidade perceptiva em reconhecer certos pormenores por parte do investigador, permitem vincular esses contrastes às variações existentes nos modos de produção e manutenção dos corpos que caracterizam respectivamente os operários e o investigador.

De facto, embora possam ser pontualmente envolvidos pelas mesmas circunstâncias do trabalho fabril, eles, os corpos dos operários e o corpo do investigador, são encarnações de histórias sociais alternativas. A aproximação etnográfica que preconizamos implica, portanto, "um esforço para demarcar e reconstruir a distância enquanto se compreende e se representa a alteridade da cultura popular e as experiências dos actores sociais a partir de uma 'perspectiva de dentro'" (Lüdtke 199:313). É o próprio intervalo que surge a separar a alteridade corporal entre operários e investigador que é sociologicamente objectivada.

Neste trabalho de pesquisa etnográfica, ao submeter o corpo próprio do investigador aos procedimentos de "objectivação participante" (Bourdieu \& Wacquant 1992:223-229), procurou-se, portanto, constituir teoricamente este corpo do investigador num termo de comparação pelo qual se pudessem avaliar as experiências corporais dos operários, as quais, embora possam permanecer mudas e inarticuladas, têm agora a sua especificidade verificada e controlada metodicamente por intermédio do contraste que mostram por comparação com as reacções somáticas do investigador. O investigador não surge como um operário entre outros, ele que apenas temporariamente esteve sobre o terreno; só que essa mesma circunstância, longe de ser uma incompletude ou lacuna da pesquisa, pode ser usada para reconstruir o processo de incorporação usualmente experimentado pelos operários e, com isso, recuperar a modulação de sentimentos, comportamentos e pensamentos tornados entretanto "naturais" para esses operários.

\section{O "jeito", a "pranta" e a "fama": o processo de incorporação de um senso prático}

Situada numa constelação de múltiplos locais de socialização quotidiana, a fábrica constitui, por si, uma experiência crucial na aquisição das disposições 
duráveis e transponíveis a fazer, a ver e a serem próprias dos operários de Rebordosa. A vivência operária da fábrica, em particular, a fricção quotidiana com o ambiente fabril ("estar fechado dentro de quatro paredes", "foi difícil ganhar aquele ritmo, sempre certinho") e com os colegas e os chefes ("aprender a ser mandado", "ver aquela gente toda de um lado para o outro") engendram uma intuição do tempo, um pressentimento dos limites e um sentido do corpo. Nas fábricas de mobiliário, a expressão "aprender a arte" resume a sucessão de momentos constitutivos da pedagogia implícita e mimética pela qual o novato adquire uma proficiência técnica e ética no ofício ("adquirindo a prática", "aprendendo a ver"). A aquisição de um ofício fortemente suportado no corpo consiste em "transmitir de modo prático, por incorporação directa, um controlo prático dos esquemas fundamentais (corporais, emocionais, visuais e mentais)" (Wacquant 2002:79).

Tornar-se operário fabril significa, assim, apropriar-se, por impregnação progressiva, do "saber indígena da profissão" (Wacquant 2002:34, 58). A assimilação é realizada através de uma aprendizagem e de uma disciplina, ou seja, um "trabalho de conversão ginástica, perceptiva, emocional e mental, que se efectua de um modo prático e colectivo, com base numa pedagogia implícita e mimética que, pacientemente, redefine, um a um, todos os parâmetros da existência" do trabalhador (Wacquant 2002:23). No caso de uma fábrica de mobiliário, trata-se de uma aprendizagem tácita que assegura, ao longo do tempo, a inculcação e a sanção pelo colectivo de trabalho de uma competência prática, que se liga a um universo de virtudes masculinas e morais e a uma relevante presteza e improvisação técnicas ("a arte"). Da reiteração de experiências semelhantes realizadas por operários colocados no interior de um mesmo local de produção circunscrito, colectivo que não raras vezes traz consigo um passado semelhante e um futuro idêntico, é todo um mesmo sistema de propensões a sentir, a fazer e a ver que se sedimenta gradualmente nos corpos e nas mentes.

A expressão "aprender a arte" resume, pois, o processo silencioso, porém pungente ("dar com os cornos no chão", "aprendi à minha custa", "sei bem o que passei para aprender a viver"), pelo qual os operários adquirem uma relação de circunspecção perante as circunstâncias envolventes, que nem assim perdem a sua percuciência e hostilidade, e que aponta para a relevância de um regime de notoriedade operária cujos princípios de avaliação se encontram ligados ao trabalho fabril. Ter "a noção da vida" ou "das coisas" equivale a interiorizar, ao longo da experiência reiterada das urgências, constrangimentos e solicitações que pesam sobre esse lugar geográfico e social, uma maneira de ver, sentir e pensar que tende a parecer a mais "apropriada" perante os eventos correntes. 
A ordem das coisas grava-se na carne e nos ossos dos operários na forma de preferências e rejeições, de simpatias e aversões, como "ir com a cara de alguém" ou, pelo contrário, "não o poder ver". "As pessoas já estão habituadas àquilo, já acham que é o normal ou até acham que aquilo deve ser assim", como nos resume Alberto, um jovem operário de 25 anos. O senso do óbvio, que se mostra nos "pressentimentos" ou num certo "saber estar", ou as pulsões viscerais ("vontade", "desenrascar") que são, em geral, inculcadas por via de um envolvimento compreensivo com os ritmos e as rotinas do trabalho são ambos mediações que contribuem para que a ordem social da fábrica seja, implícita mas continuamente, reproduzida (Burawoy 1979:77-120). Nos relatos dos operários que foram entrevistados, a compatibilização entre os corpos operários e as pressões objectivas da fábrica surge caracterizada como um tempo de progressivo envolvimento com as urgências e as promessas do trabalho, como pode ser visto nas palavras de Toni T. e Neca M.

É o tempo que a gente tem, o tempo é que o faz, é que faz com que a gente ganhe essas maneiras de trabalhar, esses ritmos. Tu estás ali para ganhar dinheiro, sabes que tens que ganhar mais ritmo, tens que te desenrascar mais depressa, e pronto. E a gente ao dia a dia vai andando, vai ganhando aquele ritmo, começa a ganhar aquilo, pronto, e nem te lembras, nem te passa [pela cabeça], é aquilo. Quando começas a trabalhar, a tua maneira de trabalhar é aquela, é assim que tu fazes. Isto já está metido na pessoa, isso é assim. Agora, se fores para ali se estiveres à espera da hora, isso não é ritmo nenhum de trabalho, não é? [...] As pessoas, depois cada uma adapta-se à maneira que quer, não é? Dentro daquilo que sabe, adapta-se. Há uns que colam gavetas e furam depois, há outros que furam antes de colar, ó pá, nem todos têm a mesma maneira de trabalhar (Toni T, 31 anos, marceneiro).

Porque essa arte é assim mesmo, fazer repetidamente as coisas e aperfeiçoá-las, é assim que se [aprende]... Pelo menos a primeira arte que eu aprendi é essa maneira de a fazer e de a aprender. [...] É quase como andar de bicicleta, não sei explicar, tu aprendes a andar de bicicleta e podes andar 30 anos, ou 40 ou 50 sem pegar numa bicicleta e, quando pegares na bicicleta, sabes andar de bicicleta, agora por quê, isso não te posso explicar. [...] É a tal coisa, são os engenheiros que pegam numa esferográfica e num papel e têm a teoria e nós a prática, não é? É isso que nos faz saber, é a prática, nós sabemos, como tu vias lá muitas vezes: "como é que você sabe que é isto para fazer isto?", é a prática. É o fazer hoje, amanhã e depois e, pronto, é prática mesmo, só isso. Não há explicações nenhumas nisso, nenhumas, uma pessoa desenha uma linha, 
concebe a linha, não é? ela começa a sair, e as primeiras vezes "como é que foi que eu fiz ao primeiro? Isto aqui? Tenho estas dúvidas?", entendes? Começa a vir uma semana, duas, acabou, depois é tudo com os olhos fechados, começa a ficar gravado na memória das pessoas, o nosso computador também funciona [aponta para a cabeça]. É assim, não há outra maneira. [...] Eu vou te responder da mesma maneira, é o gosto... É o gosto, é a vaidade de cada um naquilo que está a fazer, aquele que tiver gosto chega mais longe, faz as coisas mais bem feitas, quem não tiver para por ali, faz aquilo e não aprende, não desenvolve, acabou (Neca M., 47 anos, maquinista).

Esta vivência duradoura do lugar, ao permanecer sem necessidade de interrogação, explicação ou justificação, conforma uma totalidade de convicções, opiniões e suposições sobre o mundo, o entendimento latente e pré-reflexivo que Edmund Husserl denomina "atitude natural" (1982:5152). Ocorre como que a modulação do arco sensorial dos operários para o acomodar aos constrangimentos hierárquicos, temporais e físicos do trabalho fabril ("calejar", "habituas-te"), que passa por calibrar o limiar de tolerância emocional dos operários a um elevado grau de agressão ambiental. Nestas situações, encontramos a emergência, o aperfeiçoamento e a remodelação das "técnicas dos sentidos" (Howes 1990b:99) que tornam estes operários capazes de reagir instantânea e apropriadamente ao conjunto de exigências e urgências do trabalho fabril, assegurando o autodomínio sobre as pulsões e as sensações, o que é indispensável para atingir o controlo físico e afectivo sobre o espaço envolvente, repleto de coacções e imprevistos. Da mesma maneira, eles são assim equipados com uma aparelhagem sensorial que lhes permite pressentir e discriminar, por pequenas e passageiras que sejam, as oscilações e os matizes da atmosfera fabril.

Pode dar-se o caso de que esta imersão prolongada numa nuvem de estímulos superabundantes consista, com o tempo, em instruir uma sensibilidade peculiar à fábrica, que é o que torna possível, como escreve Karl Marx sobre o "ouvido musical" (Marx 1994:98), possuir e apreciar o contexto do trabalho fabril em termos senão prazerosos, pelo menos aceitáveis e compreensíveis. Fica-se apegado a esse espaço, ele ocupa-nos o horizonte de relevância que não só suspende a hostilidade fabril por via da habituação, como supera este momento passivo para conduzir a um investimento de si próprio sobre o trabalho, em especial sobre as interacções pessoais que nos envolvem e em que participamos diariamente ("os colegas", "os amigos").

O "regime sensorial" destes operários, que compreende as "modalidades de aprendizagem e de uso dos sentidos" (Corbin 1991:233), está biograficamente compreendido pelas sucessivas e concomitantes provas 
e provações que constituem o curso de artista da fábrica, que começa com a entrada precoce nela (para muitos operários, ocorreu entre os 12 e os 16 anos) e a relativa resiliência dos postos de trabalho (embora possíveis, são comuns as ligações muito longas com a mesma ocupação em que se começou). Em numerosas notas de campo, como a que aqui coligimos, vemos que os trabalhadores experimentam progressivamente uma absorção e uma compatibilidade perante as exigências fabris, aprimorando a acuidade que têm o seu sistema de percepções e as suas hierarquias de emoções.

1 de Março de 2007: Marco testa o rasgo que a tupia faz na peça. "Já viste? À primeira!", vangloria-se ele. Numa tarefa em que as diferenças de milímetros são importantes, é de facto espantoso. Digo-lhe isso mesmo. "Ó, são muitos anos... É o calo. Veio de mim. Eu sempre quis aprender coisas novas. Há outras pessoas que não. Que ficam paradas toda a vida. Aprendem aquilo e ficam ali. Tu tens casos desses aqui na fábrica [Olha para Tiago, marceneiro de 51 anos]. Ele não desenvolve, bloqueou". Pergunto-lhe por que terá sucedido isso. "Foram muitos anos a fazer sempre o mesmo. Só fazia aquilo [faz o gesto de colocar as mãos de cada lado dos olhos, a imitar as famosas palas dos burros]. E depois nunca teve o gosto de aprender. De ir vendo coisas novas, de procurar conhecer. Há aqui pessoas que gostam, que têm gosto no que fazem. Tão sempre a ver a maneira mais fácil para fazerem, tão sempre a inventar. Eu estou sempre a inventar coisas para fazer melhor o trabalho. E há outras pessoas que querem lá saber, 'é sempre a andar, que se lixe'. Não têm gosto no trabalho, é sempre a correr".

O senso prático que se deposita nos corpos existe como esquemas de pensamento e acção latentes que são, geralmente, apropriados a reconhecerem e a concretizarem as exigências imanentes a este quadro de interacção, a fábrica. Ao longo da trajectória biográfica singular dos operários, vai-se gravando como que um cunho social sobre a sua "estrutura de personalidade" (Elias 2004:236), resultante de uma vivência pessoal e colectiva de experiências de constrangimento e incitação que são, em larga medida, comensuráveis para os indivíduos circunvizinhos a um mesmo território físico e social, como parece ocorrer com o operariado local de Rebordosa. Esta inclusão material e social em comum certamente estimula a convergência e a concertação das disposições a ser, pensar e ver dos operários em causa.

Os operários que coexistem social e geograficamente adquirem paulatinamente um determinado modo de sentir, seja ele um palato ("gosto de coisas simples", "sem luxos", "picante"), uma entoação da voz ("só a berrar"), um registo do ouvido ("ouço as máquinas a cantar"), um certo tacto ("sinto na ponta dos dedos se a tábua está boa"), ou uma certa tolerância 
olfactiva e auditiva ("barulho"). De maneira equivalente, vai surgindo o reportório de atitudes, posturas e condutas de carga moral que são valorizadas, e aparentemente inatas, para esta ocupação ("humilde", "respeitar quem manda", "andávamos sempre limpinhos"). Esta remodelação plural das estruturas de personalidade dos operários inclui também uma mudança correspondente no seu modo de ver, o qual, se solidamente impregnado, permite perceber e interpretar com uma subtileza visual muito acentuada as impressões da realidade fabril e, em contrapartida, ignorar tudo o que pertence à paisagem e pode ser, por isso, tido-por-garantido ("ao fim dalgum tempo já não reparamos").

A concordância entre as propensões interiorizadas e o posto ocupado ajuda a explicar o à-vontade, e até o "gosto" que estes operários sentem no seu trabalho, no qual parecem realizar as expectativas e as aspirações que trazem consigo ("isto nasce com a gente") e, assim, rentabilizar um "jeito", uma "paixão" ou uma "motivação" congénitos ("isso já vem com as pessoas"). A experiência harmoniosa do mundo fabril funda-se nesse acordo tácito entre as condições de trabalho enfrentadas e os homens que estão preparados para as aceitar por terem condições de vida compatíveis. Trata-se de uma relação de pertença e de posse na qual ocorre uma "sorrateira apropriação do possuidor pelo possuído" (Merleau-Ponty 2003:34), embora ela possa ser, ocasionalmente, acometida por crises de incerteza e tensão.

Aliás, o "verdadeiro marceneiro", como afirma Mário V., um operário de 51 anos e que trabalha desde os 8, é aquele que tem "paixão pela arte" e que está habilitado a reconhecer o "valor" do trabalho. A lógica da arte realiza uma autovalorização e uma autojustificação do trabalho do operário, reconstitui em termos de "responsabilidade", "respeito" e "orgulho" os deveres e as obrigações associados às ocupações oficinais e, à semelhança da retórica redentora acerca das vantagens intrínsecas ao sacrifício, confere aos sentimentos de "gosto pelo trabalho" e "gosto pela obra bem feita" a natureza simultânea de um pressuposto e um sintoma da condição de "artista". O investimento de si no trabalho ("não preciso que ninguém me mande", "sei muito bem o que tenho que fazer", "trabalhar para a frente para ser alguém na vida") compreende-se sabendo que o trabalho tem associado a si um universo de virtudes capitais: o "jeito" técnico, a "pranta" (pose, contornos e postura corporais) e a "fama" reconhecida pelos colegas. É neste universo de virtudes que estão apoiadas a notoriedade e a reputação do "artista": "ser alguém na vida", "aprender a ser um homem", "ganhar corpo", "tirar o sustento", "ter o respeito".

Discursiva mas também materialmente, o corpo funciona para os operários como o centro nevrálgico da experiência fabril. Desde logo, porque é 
sobre ele que se depositam as maneiras de apresentação de si colectivamente sancionadas como virtuosas e as práticas de trabalho tecnicamente provadas como vantajosas, eficazes ou económicas (em todas as acepções da palavra). O "jeito" e a "pranta" designam, pois, um modo de estar e fazer sobre a fábrica, cujos princípios estão literalmente vinculados ao corpo, pois é nele que se conservam como potência e a partir dele que se materializam como actos. A memória operária imbui directamente a carnalidade operária por via do "jeito" ("tenho umas mãozinhas!", "a mão do artista não falha!", "as minhas mãos têm olhos!", "são feitas de veludo!"), suportada pela oralidade mas sobretudo por uma aprendizagem mimética do ofício ("faz como eu", "não faças assim... faz antes desta maneira", "vê primeiro como eu faço").

A "pranta" tem que ver com as posturas corporais que são tidas como correctas e legítimas pelo colectivo operário, o que permite, com um relance, avaliar a desenvoltura e a dexteridade de um trabalhador ("vi logo que estavas a fazer mal"). O trajecto de "aprender a arte" significa também professar a profissão, uma impregnação implícita do sentido do próprio lugar e das convicções a respeito da legitimidade (ou ilegitimidade) da ordem social local, bem como uma absorção dos esquemas de percepção e apreciação que permitem classificar os homens, as coisas e os acontecimentos ao longo de escalas de poluição e pureza, ou prestígio e estigma ("é bom" ou "não presta", por exemplo).

Seria complicado, porém, compreender o sentido do trabalho para os operários unicamente por recurso aos mecanismos de sujeição ao processo de trabalho fabril. A virilidade e a virtuosidade encontram no corpo um índice físico e outro moral imbricados; talvez aqueles que sejam mais imunes às arbitrariedades sociais de repartição dos recursos económicos e culturais. A investidura como "homem" e como "artista" parece, nestas circunstâncias, trazer consigo a posse de formas de valor, como o "cabedal", a coragem, o "jeito", a "pranta", a "palavra", que se acumulam e se preservam unicamente por intermédio da validação do círculo de pares, sem serem vulneráveis às intervenções de instâncias patronais ou estatais, como sucede para a entrada para um posto de chefia ou para a obtenção de um título escolar. Para estes operários, colocados em circunstâncias de escassez cultural e salarial muito acentuadas, onde são frequentes as situações de abandono escolar e as baixas remunerações salariais, o corpo constitui frequentemente o único recurso susceptível de ser rentabilizado em termos económicos e simbólicos.

No entanto, a hierarquia nativa que, em termos simples, reparte os trabalhadores consoante os seus índices de virtuosidade, separando "artistas" e "moços", tem que ser sustentada perante outros princípios de classificação, como os que produzem a escola e a empresa. O escalonamento 
formal da empresa, em termos de categorias legais e profissionais inscritas nos contratos de trabalho, expressa pela ocupação de postos hierárquicos (encarregado) ou pelas diferenças salariais, nem sempre é coincidente, e é frequentemente contradito pela opinião colectiva respeitante ao valor artístico do trabalhador em causa. Ao mesmo tempo, esta hierarquia estatutária não permanece imutável, estando constantemente exposta aos juízos e às sanções que os trabalhadores exercem sobre eles próprios e sobre os outros colegas, como sucede, por exemplo, para se punir um relacionamento muito próximo com os representantes patronais ("graxa") ou então para se valorizar a desenvoltura perante o inesperado ("é muito desenrascado").

De maneira transversal, pelo trabalho fabril, o homem "faz-se homem" em termos literais, "bota corpo" ("ganha calo", "dureza"), "aprende o que é a vida", torna-se — desejavelmente — um "artista" com "gosto" e "jeito". Nestes termos escatológicos, portanto, a fábrica simplesmente "faz bem", pois transporta consigo uma investidura ética e técnica e, para além disso, promove o acesso a uma ocupação honesta e remunerada que medeia a posse de bens de consumo. Desde logo, a necessidade familiar e o fracasso escolar que usualmente precedem a entrada para a fábrica transmutam-se parcialmente no cumprimento de uma missão ou em uma vocação ("nascemos para isto"). Nestes termos, o "artista" aparece como a personificação de um regime de notoriedade peculiar. Em contrapartida, o epíteto de "burro", "carrejão", "serviçal" ou, em termos genéricos, "moço" constituem rótulos que investem o seu portador de uma "fama" negativa, que precisa de ser tão evitada quanto a contratação persiste, em boa medida, suportada localmente na circulação de opiniões e intrigas a respeito da moralidade pessoal dos operários.

A entronização como "artista", vista como a imposição de insígnias visíveis e invisíveis ao longo do trajecto do trabalhador, constitui uma variante de "regime de acção" (Boltanski \& Thévenot 1991:425) marcado pelo percurso virtuoso que significou e obriga ao apuramento técnico e ético do operário por meio da prestação de "provas de grandeza" (:427). O "artista" tem de provar esse seu estatuto, tem de "mostrar" constantemente a sua virtuosidade (técnica, ética e estética) por intermédio das suas práticas, palavras e poses, pois esta hierarquia artística não depende apenas da perícia laboral (do volume e da qualidade da obra), mas ainda das sanções informais da sua "postura" física e moral.

Esta visão positiva e voluntariosa do trabalho fabril concilia-se com a outra narrativa que registámos, em que a exposição operária às circunstâncias ambientais da fábrica, a ruídos excruciantes ("as pessoas nem se ouviam"), a temperaturas extremas ("aquilo é que era calor"), a rotinas 
temporais rigorosas ("horas de entrar e sair") e ao custoso manuseamento de matérias-primas, máquinas e ferramentas ("pó", "perigosas") suscita e instila - simplesmente pelo condicionamento material, fisiológico, sensorial e temporal dos trabalhadores que promove e sem necessidade de impor outros regulamentos e mecanismos de controlo - uma maneira de estar, sentir e fazer que é mais do que resposta adaptativa, uma modalidade de apropriação e recriação expressiva da experiência fabril. Emerge, assim, todo um estilo de personalidade que exibe, nos pensamentos e nos comportamentos dos operários, as marcas viscerais provocadas pela submissão compulsiva às relações objectivas de (inter)dependência em vigor no espaço fabril, pela organização e o ritmo do processo de produção ("não se parava"), pela ginástica das tarefas produtivas, pela vigilância e a disciplina exercidas hierarquicamente ("eles andavam sempre em cima das pessoas", "falávamos escondidos para não nos verem"), pela coexistência num colectivo de trabalhadores que eram cooperantes e concorrentes ("conversar", "tinham raiva [i.e., inveja] uns dos outros" e, também, pelo relacionamento de reciprocidade assimétrica mantido com os patrões no âmbito do paternalismo, em que as "graças" e os "favores" patronais se intercambiam por "obrigações", "lealdade" e "responsabilidade" operárias (Sigaud 2004).

A consonância observada entre a fábrica feita coisa e a fábrica feita corpo, consonância que assegura a naturalidade, a normalidade ou a invisibilidade que podem ser sentidas ainda que se enfrentem situações violentas e hostis (vd. Scheper-Hughes 1992:224), explica-se pelo encontro entre a vertente objectiva e a vertente subjectiva do "processo de operarização ou de enfabricação" (Bourdieu 1984:252-253), vertentes que são, respectivamente, exteriorizadas nas estruturas visíveis e invisíveis do espaço social e físico da fábrica e interiorizadas nos pensamentos, comportamentos e sentimentos específicos dos operários de tal fábrica. Este trajecto será recordado pelos operários, como Toni T., como uma progressiva conformação para com as imposições, inicialmente ressentidas como um choque, que a estrutura técnica e hierárquica da fábrica coloca sobre os recém-chegados; uma conformação lenta e subtil de que emergem as tácticas de investimento de si com que o trabalhador lida com as recompensas e as penalizações do trabalho.

\section{O que mais te custou quando entraste para a fábrica?}

O tempo preso, que eu na altura ainda era novo e muitas das vezes, pronto... Eu quando não tinha conhecimentos daquilo que era, estava lá satisfeito, não era? Era aquilo que eu gostava e, depois, o tempo foi se passando e a gente em certas alturas desanimava de trabalhar e tal, aqui tanto tempo preso, e havia alturas que até me sentia assim um bocado, sei lá, estar arrependido, de dizer 
assim: "por que é que eu não escolhi outra arte", não é? Uma coisa em que andasse por fora, que é totalmente diferente de a gente estar ali quatro horas, cinco horas dentro de uma fábrica e pronto. Depois, com o tempo, um gajo vai se adaptando ao pessoal, vai se adaptando a tudo, e passa-se bem o tempo, desde o momento em que a gente esteja a fazer uma coisa que gosta. [...] Nas férias da escola [que acabaria por deixar no $6 .^{\circ}$ ano] o meu pai levava-me para a beira dele, para a gente não andar cá por fora a fazer asneiras. Ele levava-me para ali [...] só mais para estar ali preso. [...] Era que a gente fosse trabalhar, não é?, para ganhar dinheiro, para ajudar em casa, o principal de tudo. E não andássemos cá fora a fazer asneiras com ninguém, e pronto, íamos ganhando algum e estávamos ali a aprender a arte. Quando eu fui para lá trabalhar, eles davam-me quinhentos escudos por mês, não era porque eu soubesse fazer alguma coisa, era para eu começar a ganhar gosto de estar ali, estás a perceber? Para eu começar a ganhar gosto de estar ali, e o patrão mesmo chegava à minha beira e dava-me aquele dinheiro, eu ia receber como um funcionário qualquer ao escritório, chegava ali e ele: "pega lá para ti, depois entrega à tua mãe" que era para eu... [Ele] Podia pagar ao meu pai, não, pagava-me a mim que era para eu ganhar gosto, para ter motivação de querer estar ali mais, percebeste? Querer saber mais ou estar ali e não pensar noutras coisas cá fora, era aquilo (Toni T., 32 anos, marceneiro).

Realizadas ao longo de uma trajectória singular e colectiva que tem o sentido de uma progressiva habituação ("habituei-me a pouco e pouco"), esta submissão configura um modo de percepção do mundo apto a funcionar com a força da certeza. Podendo ser idiomaticamente verbalizada na forma de um senso comum fabril, a visão do mundo destes operários é orientada por princípios de classificação da realidade gerados no mundo da vida da indústria do mobiliário. Ao serem, na maioria das vezes, revelados prática, afectiva e intuitivamente, dispensando, portanto, a avaliação reflectida das circunstâncias e o planeamento deliberado da acção, estes são princípios de classificação da realidade que, tendo sido constituídos ao longo da história destas comunidades fabris, foram paulatinamente assimilados pelo operariado territorialmente enraizado. Em Rebordosa, as fábricas estão, por isso, aptas a funcionar como entrepostos onde se intersectavam as trajectórias individuais e familiares do operariado local, quadros de interacção nos quais as microssituações produzem efeitos potencialmente estruturadores sobre as redes sociais mais amplas da comunidade.

Em virtude da reiteração de interacções igualitárias ou não, da repetição de rotinas e ritmos produtivos, da resiliência e da extensão do confinamento temporal e espacial no interior da fábrica e pela generalização de 
eventos pessoais e colectivos equivalentes, os operários de Rebordosa foram conhecendo, a partir do momento da conscrição, quando começaram a ser acostumados ao ambiente fabril e treinados técnica e moralmente para o trabalho industrial, percursos laborais vincados numa sucessão de pontos de articulação pessoal e familiar semelhantes ("saí cedo da escola", "casei com uma moça daqui"), conjunturas de retracção ou expansão da economia local partilhadas ("há pouco emprego", "naquela época pagava-se bem a toda a gente") e, por consequência, assumindo projectos de futuro com traços parecidos ("ser um artista").

\section{Conclusão}

Os usos e as concepções do corpo variam entre os ofícios corporais, em particular, consoante as regras técnicas e éticas que eles suportam e o regime de notoriedade que eles promulgam (Boltanski 2004:90). Esta intersecção entre instrumentalidade, estética e moralidade de ofícios corporais surge de forma particularmente evidente no âmbito da fábrica. Juntamente com o "curso académico", os operários nomeiam um "curso na arte". Este constitui uma "carreira" na qual se cruzam um processo de aquisição de disposições apropriadas e a-propositadas para o trabalho e um processo de valorização do trabalhador. Ao longo da trajectória "como homem e como trabalhador", a fábrica constitui um espaço em que se produzem, investem e acumulam recursos de ordem técnica (a "sabedoria de marcenaria" feita de "segredos", "truques e manhas" e, fundamentalmente, de "gosto"), directamente implantados no corpo do operário. Aí se adquirem também os princípios de classificação específicos do ofício, manifestados como capacidade de reconhecer e cumprir as exigências imanentes ao quotidiano fabril e de distinguir e apreciar os homens e as coisas. De facto, o "verdadeiro marceneiro" é aquele que tem "paixão pela arte" e que está habilitado a reconhecer o "valor" do trabalho e, portanto, a separar um "falhanço" de uma "obra de categoria", ou um trabalhador "grosseiro" de um "marceneiro de primeira".

A economia da grandeza peculiar ao chão da fábrica traz reciprocamente indexados os índices técnicos, estéticos e éticos dos operários. O corpo, em especial, funciona como referencial comum de um idiolecto viril e oficinal que restitui, de modo transfigurado, a moralidade ocupacional. Esta ética prática circunscreve as virtudes oficinais por via de regras de sentimento partilhadas pelo grupo, as quais, profundamente sentidas, traçam os limites entre o "nojo" e a "paixão", as "simpatias" e as "consumições" no interior da fábrica. É pelo corpo que se manifesta a 
correlação estreita existente entre, por um lado, a aparência e os contornos corporais dos operários e, por outro lado, a sua virtuosidade masculina e oficinal ("habilidade", "desenrasco", "lanço"). "Ter jeito" e "ser jeitoso" designam, respectivamente, a posse de uma elevada habilidade técnica e uma apresentação física valorizada. O corpo é, depois, o portador de uma memória oficinal e, por isso, pode ter-se o corpo "esquecido", como quando uma trombose inutiliza o uso de um braço.

Neste artigo tivemos como preocupação principal restituir as condições sociais da incessante constituição e reconstituição da corporeidade operária, sem restringir o corpo a uma entidade semiótica, que é apenas portadora de enigmas e verdades ("linguagem dos gestos", "significado do rosto" "o segredo das emoções"), nem a uma matéria biologicamente concreta e compacta, espécie de peso vivo em que são registados e impressos passivamente os traços de uma vida que prossegue lateralmente. Ao contrário das perspectivas desencarnadas e descontextualizadas do trabalho fabril de certos estudos industriais, procuramos restituir neste artigo uma investigação sociológica do quotidiano fabril centrada na experiência vivida do trabalho operário. Através de uma pesquisa etnográfica baseada na observação participante numa fábrica de mobiliário portuguesa, procuramos interrogar sistematicamente o processo de aquisição e inculcação de uma competência simultaneamente técnica e estatutária que, realizando-se no fundamental por transmissão empática e pela implicação prática com o trabalho, caracteriza o trabalhador virtuoso, o "artista".

No chão da fábrica existe toda uma economia da grandeza oficinal, fundada numa espécie de consenso quanto aos valores intrínsecos do trabalho ("a paixão pela arte"), e que, por conseguinte, suporta a aquisição de formas de valor propriamente operárias ("jeito", "pranta", "fama"). O corpo operário pode, assim, ser visto como um conservatório de força e de virtudes e, ao mesmo tempo, como o registo em carne viva da violência e da hostilidade do trabalho fabril. "Ganhar calo" e "ganhar corpo" traduzem bem esta tensão entre acumulação e depreciação que é característica do ofício, pois ele inclui, interrelacionados, um processo de engrandecimento simbólico e corporal ("ganhar força", "ter habilidade") e um processo de usura mental e física ("esgotamento", "exploração"). Finalmente, o corpo dos operários está no centro das lutas de poder da fábrica, não apenas porque é ele que, no processo de trabalho imediato, é sistematicamente submetido ao processo de exploração capitalista a que os trabalhadores reagem, organizada e espontaneamente, tentando assegurar a sua poupança e conservação, mas também porque é nele que são concentrados os índices simbólicos da distinção operária, tais como a pose, a força ou a habilidade. 
Bruno Monteiro é pós-doutorando no Instituto de Sociologia, Universidade do Porto, Portugal. E-mail: < bjrmonteiro@gmail.com>

\section{Notas}

${ }^{1}$ Embora seja impossível proceder a uma minuciosa sociografia de Rebordosa, podemos proporcionar indicadores estatísticos relevantes que permitem, em termos sucintos, traçar as linhas de força mais salientes sobre esta comunidade. Para tanto, recorremos aos elementos proporcionados pelo Recenseamento Geral da População (2001). Em termos escolares, note-se que o concelho de Paredes, em que se situa Rebordosa, apresentava, nesse ano, taxas de abandono $(6,4 \%)$ e de saída antecipada da escola $(51,6 \%)$ significativamente superiores às mesmas taxas verificadas para o conjunto de Portugal (que eram, respectivamente, 2,8\% e 26,5\%). Em sentido inverso, as taxas de conclusão do ensino secundário (10,1\%) e do ensino superior $(6,3 \%)$ tinham, em Paredes, valores consideravelmente inferiores aos apresentados para o território nacional (por esta ordem, 16,5\% e 13,3\%). Sem poder prolongar esta caracterização, é importante notar que, em 2001, a indústria do mobiliário ocupava uma proporção muito ampla dos trabalhadores do concelho de Paredes, representando 45,4\% do total de activos do sector secundário (e 27,3\% da população activa concelhia).

${ }^{2} \mathrm{O}$ recenseamento industrial dedicado ao sector do mobiliário no concelho de Paredes contabilizava, em 2005, 1.166 empresas, 258 delas na freguesia de Rebordosa, onde está situada a empresa K. No geral, trata-se de microempresas (em média, cada qual conta com oito trabalhadores; 851 empresas têm dez ou menos trabalhadores), extremamente voláteis (436 foram criadas nos dez anos anteriores à realização do estudo), com uma estrutura produtiva tradicional (como evidencia a reduzida presença de trabalhadores administrativos - 827 num total contabilizado de 8.439 - e a subcontratação generalizada dos serviços de gestão financeira - 973 empresas estão nessa situação) e dedicados sobretudo à revenda e à subcontratação (912 empresas afirmam dedicar-se à revenda, 836 empresas não têm exposição própria, 742 fazem móveis por medida). 


\section{Referências bibliográficas}

BACHELARD, Gaston. 1960. Le rationalisme appliqué. Paris: PUF.

BAXANDALL, Michael. 1988. Painting and experience in fifteenth century Italy. Oxford: Oxford University Press.

BIERNACKI, Richard. 1995. The fabrication of labor: Germany and Britain, 1640-1914. Berkeley: University of California Press. BOLTANSKI, Luc. 2004. As classes sociais e o corpo. $4^{\mathrm{a}}$ ed. São Paulo: Paz e Terra. - \& THÉVENOT, Laurent. 1991. De la justification. Les economies de la grandeur. Paris: Éditions Gallimard. BOURDIEU, Pierre \& WACQUANT, Loïc. 1992. Réponses. Pour une anthropologie refléxive. Paris: Éditions du Seuil. - 1984. Questions de sociologie. Paris: Éditions du Minuit. 2003. Méditations Pascaliennes. Paris: Éditions du Seuil.

BURAWOY, Michael. 1979. Manufacturing consent. Changes in the labor process under monopoly capitalism. Chicago: Chicago University Press.

1991. "Introduction". In: Michael Burawoy et al. (eds.), Ethnography unbound. Power and resistance in the modern metropolis. Berkeley: University of California Press. pp. 1-7.

CHARLESWORTH, Simon. 2000. A phenomenology of working class experience. Cambridge: Cambridge University Press.

CORBIN, Alain. 1991. Le temps, le désir et l'horreur. Paris: Aubier.

CSORDAS, Thomas. 1990. "Embodiment as a paradigm for anthropology". Ethos, 181:5-47.

ELIAS, Norbert. 2004. A sociedade dos indivíduos. $2^{\mathrm{a}}$ ed. Lisboa: Publicações D. Quixote.

GOFFMAN, Erving. 1989. "On fieldwork". Journal of Contemporary Ethnography, 18:123-132.
HOWES, David. 1990a. "Controlling textuality: a call for a return to the senses". Anthropologica, 321:55-73. - 1990b. "Les techniques des sens". Anthropologie et Societés, 142:99-115.

HUSSERL, Edmund. 1982. Ideas pertaining to a pure phenomenology. Vol. 1 . The Hague: Martinus Nijhoff Publishers.

LOPES, José Sérgio Leite. 1976. O vapor do diabo. O trabalho dos operários do açúcar. Rio de Janeiro: Paz e Terra.

LÜDTKE, Alf. 1995. "Introduction: what is the history of everyday life and who are its practitioners?". In: Alf Lüdtke (ed.), The history of everyday life. Reconstructing historical experiences and ways of life. Princeton: Princeton University Press. pp. 3-40.

MARX, Karl. 1994. Manuscritos económico-filosóficos de 1844. Lisboa: Editorial Avante!

MERLEAU-PONTY, Maurice. 2003. Palestras. Lisboa: Edições 70.

NIETHAMMER, Lutz. 2012. "Fragen Antworten - Fragen. Methodische erfahrungen und erwägungen zur Oral History". In: Julia Oberteis (ed.), Oral history. Stuttgart: Franz Steiner Verlag. pp. 31-71.

QUEIRÓS, João \& PINTO, José Madureira. 2010. "Relação com a escola e modelo de desenvolvimento". In:___ (orgs.), Ir e voltar. Sociologia de uma colectividade local do noroeste português 1977-2007. Vol. 1. Porto: Edições Afrontamento. pp. 275-318.

ROY, Donald. 2006. Un sociologue à l'usine. Textes essentiels pour la sociologie $d u$ travail. Paris: Éditions La Découverte. SCHEPER-HUGHES, Nancy. 1992. Death without weeping. The violence of everyday life in Brazil. Berkeley: University of California Press. 
SIGAUD, Lygia. 2004. "Armadilhas da honra e do perdão: usos sociais do direito na mata pernambucana". Mana. Estudos de Antropologia Social, 10(1):131-163. WACQUANT, Loïc. 2002. Alma e corpo. Notas etnográficas de um aprendiz de boxe. Rio de Janeiro: Relume Dumará. WATTS, Richard. 2003. Politeness. Cambridge: Cambridge University Press. 
Resumo

Este texto visa expor a lógica moral e sensual do universo fabril, tentando suplementar as leituras excessivamente técnicas do trabalho com um estudo contextualizado e encarnado das práticas operárias. Nesse sentido, o investigador procedeu a um trabalho de observação participante, trabalhando 14 semanas, em 2007, como operador de máquina numa fábrica de mobiliário do Noroeste português. Um ano mais tarde, em 2008, ele voltaria para estudar a comunidade envolvente por mais 16 semanas. A partir da objectivação sociológica da experiência visceral do trabalho, foi possível conhecer o processo de incorporação do senso prático dos trabalhadores, conhecido localmente como "aprender a arte". Dada a sua relevância, é concedida uma atenção particular às implicações que teve o recurso à observação participante para esta pesquisa sociológica.

Palavras-chave Etnografia, Incorporação, Operariado, Senso prático, Regime de notoriedade.

\section{Abstract}

This article explores the moral and sensual logic of work, complementing excessively technical interpretations through the study of the contextualized and embodied practices of workers. To this end, I conducted participant observation research in 2007, working as a machine operator in a furniture plant in Portugal for a period of 14 weeks. One year later I returned to study the surrounding community for a further 16 weeks. Through the sociological objectivation of the visceral experiences of work, it was possible to apprehend the embodiment of practical sense, which is locally known as "learning the art". Due to its methodological relevance, special attention is paid to the consequences of participant observation in research of this nature.

Key words Ethnography, Embodiment, Working class, Practical sense, Regime of notoriety. 